\title{
Comparative evaluation of anopheline sampling methods in three localities in Indonesia
}

Brandyce St. Laurent ${ }^{1,6^{*}} \mathbb{D}$, Supratman Sukowati ${ }^{\wedge}$, Timothy A. Burton ${ }^{1}$, David Bretz ${ }^{1}$, Mulyadi Zio ${ }^{2}$, Syah Firman², Sumardi ${ }^{2}$, Heru Sudibyo², Amalia Safitri², Suwito², Puji B. Asih ${ }^{3}$, Sully Kosasih ${ }^{3}$, Shinta², William A. Hawley ${ }^{4,5}$, Thomas R. Burkot ${ }^{7}$, Frank H. Collins ${ }^{1}$, Din Syafruddin ${ }^{3}$ and Neil F. Lobo ${ }^{1}$

\begin{abstract}
Background: The effectiveness of vector control efforts can vary based on the interventions used and local mosquito behaviour and adaptability. In many settings, biting patterns of Anopheles mosquitoes can shift in response to interventions targeting indoor-biting mosquitoes, often resulting in higher proportions of mosquitoes feeding outside or at times when people are not protected. These behaviourally resistant mosquitoes have been shown to sustain residual malaria transmission and limit control efforts. Therefore, it is important to accurately sample mosquitoes to understand their behaviour.

Methods: A variety of traps were evaluated in three geographically diverse sites in malaria-endemic Indonesia to investigate local mosquito feeding behaviour and determine effective traps for surveillance.

Results: Eight traps were evaluated in three sites: Canti village, Lampung, Kaliharjo village, Purworejo, and Saketa village, Halmahera, Indonesia, including the gold standard human landing collection (HLC) and a variety of traps targeting host-seeking and resting mosquitoes both indoors and outdoors. Trapping, using indoor and outdoor HLC, the Ifakara tent trap C, goat and human-occupied tents, resting pots and boxes, and CDC miniature light traps was conducted for 16 nights in two sites and 8 nights in a third site, using a Latin square design. Trap efficacy varied by site, with outdoor HLC yielding the highest catch rates in Canti and Kaliharjo and a goat-baited tent trap proving most effective in Saketa. In Canti village, anthropophilic Anopheles sundaicus were caught indoors and outdoors using HLCs, peaking in the early morning. In Kaliharjo, a variety of mosquitoes were caught, mostly outdoors throughout the night. HLC was ineffective in Saketa, the only site where a goat-baited tent trap was tested. This trap was effective in catching zoophilic vectors outdoors before midnight.

Conclusions: Different trapping methods were suitable for different species, likely reflecting differences in behaviour among species. The three villages, each located on a different island in the Indonesian archipelago, contained mosquito populations with unique behaviours. These data suggest that the effectiveness of specific vector monitoring and control measures may vary by location.
\end{abstract}

Keywords: Anopheles, Sampling, Vector ecology, Indonesia, Malaria

\footnotetext{
*Correspondence: brandyce.stlaurent@nih.gov

$\wedge$ Deceased

${ }^{6}$ National Institutes of Health, Bethesda, MD, USA

Full list of author information is available at the end of the article
} 


\section{Background}

Between the introduction of the UN Millennium Development Goals in 2000 and 2015, incidence of malaria is estimated to have decreased by $37 \%$. In much of Africa, this reduction is attributed to the roll-out of vector control using insecticide-treated nets (ITNs) or indoor residual spray (IRS), although the effect of these interventions in the rest of the world is less understood [1, 2]. Recent studies have shown a large diversity of vector species in endemic areas, a number of which may exhibit behaviour not targeted by existing control measures [3-5]. In many settings, biting patterns of Anopheles mosquitoes are shifting and insecticide resistance alleles are becoming widespread, presumably in adaptation to deployed vector control measures [6-12]. On a local level, understanding the species and behavioural diversity of resident anophelines is crucial for developing and targeting vector interventions [13].

To adequately survey local vector species, efficient sampling methods that capture relevant (i.e., human biting) vectors are needed. All sampling methods have their respective biases as they target different aspects of mosquito behavioural patterns, and some are only useful in particular environments [14]. The choice of sampling method is largely influenced by local species-specific behaviour and the entomological endpoint of interest (e.g., indoor/outdoor biting rates, biting times, bloodfeeding preference, and resting locations of blood-fed mosquitoes) $[15,16]$. Further, different locations within the same region can have entirely distinct vector communities. Therefore, it is important to evaluate mosquito sampling methods in various malaria-endemic regions with inter-regional vector diversity that may arise from differing climates, human activity patterns, seasonality, or other inherent ecological or entomological differences.

The gold standard for directly measuring human exposure and risk of malaria infection is the human landing collection (HLC), where a human collector sits with their legs exposed and captures mosquitoes seeking a blood meal. These collections potentially under-represent secondary vectors that only occasionally feed on humans, creating difficulty in assessing these species' contributions to disease transmission. HLCs are also labour and cost intensive, and can be subject to local government and/or institutional review board (IRB) restrictions due to ethical concerns of collector safety [17], as well as being variable depending on the skill and mosquito attractiveness of the collectors. Several exposure-free traps have been developed to collect Anopheles mosquitoes attracted to humans $[18,19]$, including the Ifakara tent trap (ITT). Several iterations of the ITT have been tested in Tanzania and other countries in Africa and shown to be effective for collecting anthropophilic, indoor-biting malaria vectors such as Anopheles gambiae $[16,20-22]$. The ITT was developed for collecting African malaria vectors, and had not been previously tested in Southeast Asia. In general, Indonesian anopheline mosquitoes do not favour entering 'enclosed' houses or traps (Laurent, Lobo, Malaria Transmission Consortium (MTC), unpublished). Few collection methods have been evaluated at any site in Indonesia, and many studies evaluating the distribution of malaria vectors are based on larval collections [23, 24].

This trap evaluation study was conducted in Indonesia, a geographically and ecologically varied archipelago with a large number of anopheline species. The country faces ongoing malaria transmission with an estimated 3.2-5.3 million cases in 2013 [2]. ITNs are presently estimated to be available to about $50 \%$ of the at-risk population, up from $20 \%$ at the time of this study in 2009 [2]. Distributions of anopheline species vary throughout the country, complicating transmission dynamics and potentially influencing the effectiveness of distributed ITNs.

The purpose of this study is to evaluate the best anopheline sampling methods in various transmission settings within Indonesia for continued mosquito collections, and to characterize resident primary and secondary vectors that may exhibit various bionomic traits (indoor/outdoor biting; anthropophagic/zoophagic, time of biting). Three villages were chosen as study sites to reflect different ecological and malaria transmission settings. Eight collection methods were tested in a Latin-square design to compare trap efficacy in each site. HLC (indoor and outdoor) was compared to two different sized human-occupied tents, the Ifakara tent trap C, CDC light traps, resting boxes (indoor and outdoor), resting pots (indoor and outdoor), and, in one site, a goat-baited tent trap. HLCs and tent trap collections were conducted hourly to study temporal patterns of activity. Since these traps may rely on different stimuli to capture mosquitoes and attractive cues may differ between species, the evaluation of their effectiveness was stratified by mosquito species.

\section{Methods \\ Site description}

These studies were carried out in three villages of varying transmission intensities across Indonesia (Fig. 1) during the period of peak mosquito densities, when possible. This period selected for trap evaluation were based on data from longitudinal collections over the preceding 2 years (Sukowati, pers. comm.).

\section{Lampung-Canti village}

This village is situated in western Indonesia, on the southern coast of Sumatra. This area is characterized by low to intermediate seasonal malaria endemicity. Houses 

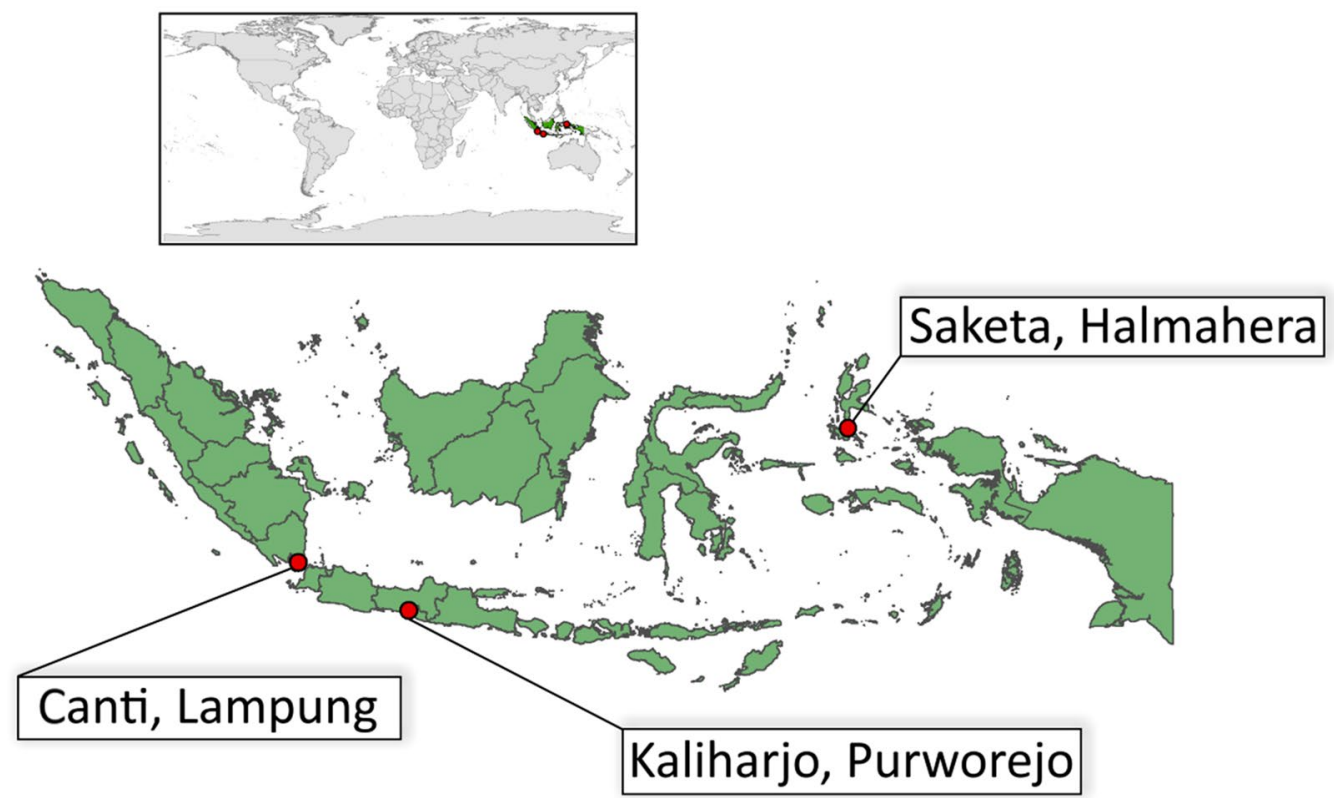

Fig. 1 Locations of three collection sites across Indonesia. Sites of mosquito collection are labelled by village and province (referenced by village name in the text). Canti, Lampung; Kaliharjo, Purworejo; Saketa, Halmahera

representing local construction were randomly chosen, and were often adjacent to shrimp and fish farming facilities. Houses are typically made of brick or wood and plaster, with tiled roofs, and tend to have screens on some windows and eaves. Predominant activities in the area include fishing and shrimp farming that create slightly saline larval habitats which can be exploited by Anopheles sundaicus, the primary vector in this area [25]. This portion of the study was conducted over 16 nights in May-June, 2009.

\section{Purworejo-Kaliharjo village}

This village is situated in a highly forested and hilly area of central Java, with extremely low malaria incidence. Despite occasional epidemics, this area has been targeted for elimination of malaria. The primary land use surrounding the village is terraced rice farming. Houses are brick, wood, or thatch siding with tiled roofs. Structures have many holes and openings that allow mosquito entry and exit. Anopheles aconitus and Anopheles balabacensis are the most commonly collected local vectors using HLCs, with population peaks in February and July $[26,27]$. Anopheles aconitus is a primary vector in other parts of central Java [27]. This portion of the study was conducted over 16 nights in July, 2009.

\section{Halmahera-Saketa village}

This village is located on the southwestern coast of Halmahera island in the North Maluku islands in eastern
Indonesia. The region has the highest reported levels of malaria of the three study sites. However, longitudinal studies using HLCs have resulted in such low catches of Anopheles mosquitoes that trends in mosquito biting rates have been hard to determine (Sukowati, MTC, unpublished data). The area primarily consists of small fishing villages along the coast, with houses typically made of wood and plaster and metal rooftops. Many houses have open eaves, doors, and windows that allow mosquito entry and exit. This portion of the study took place over 8 nights in August, 2009, rather than the 16 nights in the other two sites, due to local political circumstances.

\section{Mosquito collection}

Human landing collections took place from 18:00 to 06:00 each night. Trained collectors sat with their legs exposed and used a mouth aspirator and flashlight to collect landing mosquitoes. Indoor collectors sat inside a house, and outdoor collectors sat outside in a dark area. Mosquitoes were stored in a paper cup and collected every hour for processing. Collectors worked in 6-h shifts, switching collectors at midnight. Collectors were rotated indoors and outdoors to prevent bias associated with innate differences in attractiveness of individuals to mosquitoes.

The large tent traps were screen tents approximately $3 \mathrm{~m} \times 5 \mathrm{~m}$ and $2 \mathrm{~m}$ high (Insta-Clip Six-sided Screen House, The Coleman Company, Inc.) placed outdoors. The tent is 6-sided with two doors on opposite sides, and 
is designed to be easily set up and taken down. A sleeping human was protected within a smaller, closed tent ('Bug Hut' 2-person tent, REI) inside the larger tent. In Saketa village, Halmahera, a goat-baited tent was also tested, wherein a goat was leashed loosely to a stake in the centre of the large tent. In both versions of the tent trap, mosquitoes resting on the inner walls of the large tent were collected using a mouth aspirator once per hour from 18:00 to 06:00.

The small tent traps were approximately $2 \mathrm{sq} \mathrm{m}$ ('Bug Hut' 2-person tent, REI) with a sleeping human protected within a smaller tent (Iguana BedNets 1-person pop-up tent, Iguana, LLC) inside. The tents were placed outdoors, and mosquitoes were collected hourly in the same manner as with the larger tent traps from 18:00 to 06:00.

The Ifakara tent trap C (ITT-C) has conical entry points on four sides that point inward, theoretically allowing mosquito entry to the upper part of the ITT-C but inhibiting exit. Inside the tent, a sleeping human on the ground level of the trap was protected from bites by a protective mesh barrier [16, 28]. The upper part of the trap was searched for mosquitoes at 06.00 , to collect mosquitoes that may have entered from 18:00 to 06:00. The ITT-C was placed outside, but has recently been considered to represent an indoor-type environment [28].

Resting boxes were wooden 5 -sided cubes, about $0.5 \mathrm{sq}$ $\mathrm{m}$ per side and lined with black felt and open on one side. Resting pots were made locally from red clay, with fabric covering half the opening. To provide humidity, pots were moistened before use. These traps are intended to capture mosquitoes resting after blood meals, rather than those that are host seeking, and are constructed to create attractive resting spots. Two resting boxes and two resting pots were placed indoors, and two of each outdoors each night from 18:00 to 06:00. Resting boxes and pots were checked for resting mosquitoes in the morning, which were collected using mouth aspirators.

CDC light traps (CDC-LT) were placed indoors next to a human sleeping under an untreated bed net, which has been shown to increase trap efficiency by providing a $\mathrm{CO}_{2}$ and odourant source. The CDC-LT contains a battery-powered light above a fan that pulls mosquitoes through into a collection container. The protected human under the bed net serves as an attractive lure to bring host-seeking mosquitoes to the area for capture by the light trap. The light also serves as an attractant for some mosquito species. The light traps were set from 18:00 to 06:00 each night, and mosquitoes were collected in the morning.

To mitigate night and location effects, a $4 \times 4$ Latin square design was used for comparative evaluation of mosquito traps at each of the three sites (Table 1). These eight traps were evaluated in each of three sites previously described. Additionally, a goat-baited tent using the same tent as the large tent trap was tested in the high transmission site in Saketa village. Sampling sites were at least $100 \mathrm{~m}$ apart and tent traps were situated at least $10 \mathrm{~m}$ away from each other and the houses near where they were being tested to prevent trapping methods from impacting each other within the same household.

\section{Sample processing}

Mosquitoes were collected using mouth aspirators from ITT, large and small tent traps, and HLC hourly from 18:00 to 06:00. Mosquitoes in resting pots, resting boxes, and CDC light traps were collected once in the morning between 06:00 and 06:30. Collections from each hour and for each trap type were held separately in paper cups until processing and morphological identification in the field [29].

Genomic DNA was isolated from individual specimens using a CTAB DNA extraction. A sequence of the ribosomal DNA internal transcribed spacer region two (rDNA ITS2) was used for molecular identification of mosquito species. This particular region, useful for differentiating Anopheles species complexes, is amplified using PCR with ITS2A and ITS2B primers [30]. This analysis was done on a small set of samples to confirm the presence of

Table 1 Sampling schematic of a single round in one block

\begin{tabular}{|c|c|c|c|c|}
\hline & \multicolumn{4}{|l|}{ House } \\
\hline & 1 & 2 & 3 & 4 \\
\hline $\begin{array}{c}\text { Day } \\
1\end{array}$ & HLC indoors and outdoors & $\begin{array}{l}\text { Resting pots and boxes indoors } \\
\text { and outdoors }\end{array}$ & $\begin{array}{l}\text { ITT-C outdoors and CDC-LT } \\
\text { indoors }\end{array}$ & Small and large tent traps outdoors \\
\hline $\begin{array}{c}\text { Day } \\
2\end{array}$ & $\begin{array}{l}\text { Small and large tent traps } \\
\text { outdoors }\end{array}$ & HLC indoors and outdoors & $\begin{array}{l}\text { Resting pots and boxes indoors } \\
\text { and outdoors }\end{array}$ & ITT-C outdoors and CDC-LT indoors \\
\hline $\begin{array}{c}\text { Day } \\
3\end{array}$ & $\begin{array}{l}\text { ITT-C outdoors and CDC-LT } \\
\text { indoors }\end{array}$ & $\begin{array}{l}\text { Small and large tent traps } \\
\text { outdoors }\end{array}$ & HLC indoors and outdoors & $\begin{array}{l}\text { Resting pots and boxes indoors } \\
\text { and outdoors }\end{array}$ \\
\hline $\begin{array}{c}\text { Day } \\
4\end{array}$ & $\begin{array}{l}\text { Resting pots and boxes indoors } \\
\text { and outdoors }\end{array}$ & $\begin{array}{l}\text { ITT-C outdoors and CDC-LT } \\
\text { indoors }\end{array}$ & $\begin{array}{l}\text { Small and large tent traps } \\
\text { outdoors }\end{array}$ & HLC indoors and outdoors \\
\hline
\end{tabular}

A goat-baited tent was added to the sampling scheme with the resting pots and boxes only in Saketa, Halmahera 
vector species. Not all of the collected samples were available to sequence for molecular species identity based on ITS2 sequence. The amplified fragments were visualized by electrophoresis on a $1 \%$ agarose gel. Prior to sequencing, fragments were purified using an enzyme cleanup: $2 \mathrm{U}$ of Exonuclease I (USB Corp, Cleveland, OH, USA), $1 \mathrm{U}$ of Shrimp Alkaline Phosphatase (USB), and $1.8 \mu \mathrm{l}$ of $\mathrm{ddH} 20$ were added to $8 \mu \mathrm{l}$ of PCR product and incubated at $37^{\circ} \mathrm{C}$ for $15 \mathrm{~min}$ followed by inactivation at $80{ }^{\circ} \mathrm{C}$ for $15 \mathrm{~min}$. Purified products were sequenced directly using Sanger sequencing on an ABI 3730 xl DNA Analyzer Platform (Applied Biosystems). The ITS2 sequences were blasted against the NCBI GenBank nr database using BLASTn for molecular species identification.

The infection status of captured mosquitoes specimens was determined using the standard sandwich ELISA test for the detection of Plasmodium falciparum, Plasmodium vivax-210 and Plasmodium vivax-247 circumsporozoite (CS) proteins [31]. A subset of mosquitoes were analysed for Plasmodium infection using a multiplex PCR designed to detect $P$. falciparum and $P$. vivax [32].

\section{Statistical analysis}

The mean catch differences between sampling methods were analysed independently for each site. The $\log (x+1)$ transformation was used to achieve a normal distribution in the numbers of caught mosquitoes, and this transformed value was treated as the dependent variable and compared using ANOVA. The null hypothesis was there was no difference in nightly anopheline catch between sampling methods (no trap effect). A post hoc Tukey's HSD test was performed to determine statistically significant differences between total catch due to trap and location effects in the experiment. These tests were performed using GraphPad Prism version 7.02 for Windows (GraphPad Software, La Jolla CA, USA).

Trap efficacy was evaluated in comparison to HLCs. Efficacy was estimated by dividing the mean trap catch by the mean HLC. Outdoor traps were compared to outdoor HLC and indoor traps were compared to indoor HLC. Relative catch numbers could only be compared for the trap evaluation in Canti due to the low catch rates in Kaliharjo and Saketa.

\section{Results}

The number and species composition of Anopheles mosquitoes caught differed among the three study sites. In Canti village, Lampung, a total of 2353 anophelines were collected over 16 nights; all were morphologically identified as An. sundaicus. A sub-set $(\mathrm{n}=68)$ of these mosquitoes were molecularly identified as Anopheles epiroticus (An. sundaicus species A) by ITS2 analysis (Table 2). In Kaliharjo village, Purworejo, 286 total anophelines were collected over 16 nights; they were morphologically identified as An. aconitus ( $\mathrm{n}=228)$, An. balabacensis $(\mathrm{n}=46)$, Anopheles barbirostris $(\mathrm{n}=11)$, and Anopheles vagus $(\mathrm{n}=1)$ (Table 2$)$. In Saketa village, Halmahera, 75 anophelines were collected over 8 nights; these were morphologically identified as An. vagus $(\mathrm{n}=41)$, Anopheles farauti $(\mathrm{n}=18)$, Anopheles kochi $(\mathrm{n}=8)$, Anopheles tessellatus $(\mathrm{n}=6)$, and An. barbirostris $(\mathrm{n}=2)$ (Tables 2 and 3).

There was a statistically significant trap effect on the mean daily catch of anophelines at each site, though overall trap effectiveness varied by site. The majority of specimens in Canti were collected by HLC, with 1277 and 827 in outdoor HLCs and indoor HLCs, respectively (Fig. 2a; Table 4). Large and small exposure-free tent traps collected 104 and 82 total anophelines, respectively, and the ITT-C collected 13. The indoor CDC light trap collected 41 anophelines; indoor and outdoor resting traps contributed very little to the overall collection numbers (Table 4). The collection method had a significant effect on the total number of captured anopheline mosquitoes (Table 4, ANOVA; $\mathrm{F}=150.2, \mathrm{p}<0.0001$ ) and a post hoc Tukey's HSD test revealed that there was no significant difference between indoor/outdoor HLCs, though they were both significantly different from other traps (Additional file 1: Table S1, Tukey's HSD; $\mathrm{p}<0.0001$ ). The large and small tent traps were not significantly different

Table 2 Anopheles species collected by study site

\begin{tabular}{|c|c|c|c|c|}
\hline & $\begin{array}{l}\text { Canti, } \\
\text { Lampung }\end{array}$ & $\begin{array}{l}\text { Kaliharjo, } \\
\text { Purworejo }\end{array}$ & $\begin{array}{l}\text { Saketa, } \\
\text { Halmahera }\end{array}$ & Total \\
\hline An. aconitus & & 219 & & 219 \\
\hline $\begin{array}{l}\text { An. balaban- } \\
\text { censis }\end{array}$ & & 42 & & 42 \\
\hline An. barbirostris & & 11 & 2 & 13 \\
\hline An. farauti & & & 18 & 18 \\
\hline An. kochi & & & 8 & 8 \\
\hline An. sundaicus & 2350 & & & 2350 \\
\hline An.tesselatus & & & 6 & 6 \\
\hline An. vagus & & 1 & 41 & 42 \\
\hline Total & 2350 & 273 & 75 & 2695 \\
\hline
\end{tabular}

Species were determined by morphological identification 
Table 3 Collection method by species in three study sites

\begin{tabular}{|c|c|c|c|c|c|c|c|c|c|c|c|}
\hline & $\begin{array}{l}\mathrm{HLC} \\
\text { in }\end{array}$ & $\begin{array}{l}\text { HLC } \\
\text { out }\end{array}$ & $\begin{array}{l}\text { Large } \\
\text { tent }\end{array}$ & $\begin{array}{l}\text { Small } \\
\text { tent }\end{array}$ & ITT & $\begin{array}{l}\text { CDC- } \\
\text { LT }\end{array}$ & $\begin{array}{l}\text { Resting box } \\
\text { in }\end{array}$ & $\begin{array}{l}\text { Resting box } \\
\text { out }\end{array}$ & $\begin{array}{l}\text { Resting } \\
\text { jar in }\end{array}$ & $\begin{array}{l}\text { Resting jar } \\
\text { out }\end{array}$ & Total \\
\hline An. aconitus & 12 & 205 & 1 & & & & 1 & & & & 219 \\
\hline An. balabancensis & 2 & 33 & 5 & 2 & & & & & & & 42 \\
\hline An. barbirostris & & 5 & 5 & 1 & 1 & & & & & 1 & 13 \\
\hline An. farauti & & 4 & & & & 1 & & & & 13 & 18 \\
\hline An. kochi & & & 2 & & & & & & & 6 & 8 \\
\hline An. sundaicus & 827 & 1277 & 104 & 82 & 13 & 41 & 2 & 2 & 3 & 2 & 2353 \\
\hline An. tesselatus & 3 & 2 & 1 & & & & & & & & 6 \\
\hline An. vagus & & 8 & & & & & & & & 34 & 42 \\
\hline Total & 844 & 1534 & 118 & 85 & 14 & 42 & 3 & 2 & 3 & 56 & 2701 \\
\hline
\end{tabular}

Total numbers of eight anopheles species collected in each type of trap across all sites

from each other but were significantly different from other traps (Additional file 1: Table S1, Tukey's HSD; $\mathrm{p}<0.0001$ ). The CDC-LT was significantly different from the resting traps, but there were no significant differences between the ITT-C and the resting traps both in and outdoors. There was a significant location effect (ANOVA, $p=0.033$ ), with one house significantly different than the other three tested.

The efficiency of each type of trap in Canti was directly compared to catch rate of HLCs (Table 5). The CDC-LT and indoor resting pots and boxes were treated as indoor collections and compared with indoor HLCs, while all other traps were considered outdoor collections and compared with outdoor HLCs. All traps yielded lower numbers of An. sundaicus per night when compared to HLCs (Table 5). The large and small tent traps were the most effective alternatives, respectively yielding 8.1 and $6.4 \%$ compared to mean outdoor HLC. All other traps yielded less than $1 \%$ compared to HLC.

Of 2347 An. sundaicus samples collected in Canti and screened by ELISA and sporozoite diagnostic PCR, 9 were found to be positive for $P$. falciparum and 62 were positive for $P$. vivax (Table 6). Of the $P$. falciparum positive specimens, 3 were captured with indoor HLC and 6 were captured with outdoor HLC. Of the $P$. vivax positive specimens, 16 were captured indoors with HLC, 31 were captured with outdoor HLC, 5 were captured in the indoor CDC-LT, 3 were captured in the large outdoor human-occupied tent, and 3 were captured in the small outdoor human-occupied tent (Table 6). In total, the sporozoite rates in Canti were $2.6 \% P$. vivax and $0.4 \% P$. falciparum (Table 6).
In Kaliharjo, the majority of the 273 anophelines were captured in outdoor HLC, with 243 mosquitoes collected in these traps over 16 nights (Fig. 2b; Table 4). Indoor HLC yielded 14 mosquitoes; the large and small tent trap collected 11 and 3 anophelines, respectively. ITT-C and indoor resting boxes yielded one mosquito each over the collection period, and no mosquitoes were collected in the remaining traps. Outdoor HLC was significantly more effective than all other collection methods (Additional file 1: Table S1, Tukey's HSD; $\mathrm{p}<0.0001$ ) and there was a significant trap effect (Table 4, ANOVA, $\mathrm{p}<0.001$ ). Indoor HLC and the large tent trap caught fewer anophelines and were statistically similar to each other, and all remaining traps were statistically similar (Additional file 1: Table S1). There was no trap location effect.

Of 220 samples analysed from Kaliharjo, 1 was PCR positive for $P$. vivax, and 1 was ELISA positive for $P$. vivax 247 , a $0.7 \%$ overall $P$. vivax sporozoite positivity rate (Table 6). Both positive samples were captured with indoor HLC. These specimens were confirmed to be $A n$. aconitus from ITS2 sequences.

In Saketa, a total of 63 anophelines were collected, with the majority collected in goat-baited large tent (Fig. 2c; Table 4). Fifty-four mosquitoes were captured in these traps over eight nights, compared to three mosquitoes captured in the human-occupied large tent over the same period. Indoor and outdoor HLCs yielded 3 and 2 anophelines, respectively. One mosquito was captured in the indoor CDC-LT. There was a significant trap effect for the goat-baited trap compared to other trapping methods (Table 4; Additional file 1: Table S1, Tukey's HSD; $\mathrm{p}<0.0001$ ), as well as a significant location effect 

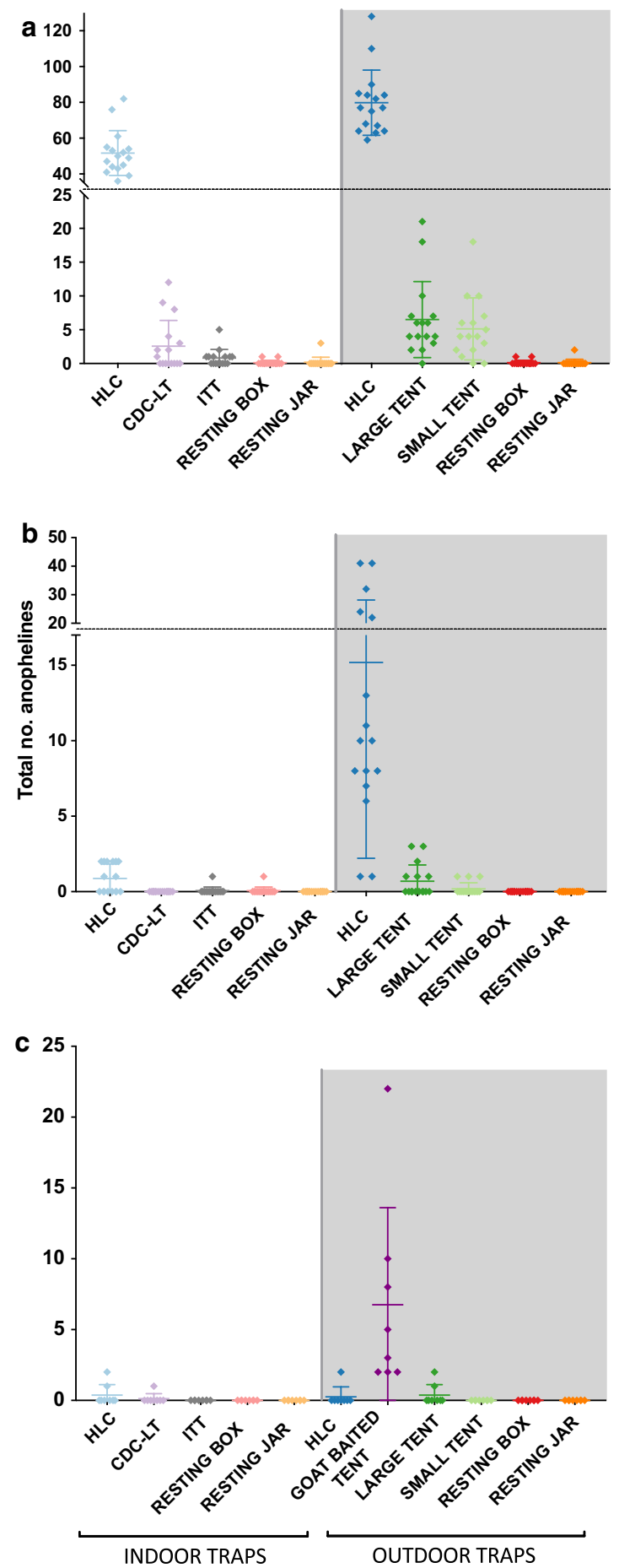

Fig. 2 Total anophelines per trap over 16 catch nights. (Individual markers indicated collections from a single night in that trap at that location) in a Canti village, Lampung, indicating an anthropophilic population that prefers to feed outdoors but also feeds indoors. $\mathbf{b}$ Kaliharjo village, Purworejo, indicating an anthropophilic population that prefers to feed outdoors. c Saketa village, Halmahera, indicating a zoophilic population that prefers to feed outdoors. Traps are arranged by indoor (white background) and outdoor (grey background) traps. Note that a goat-baited tent was only evaluated in Saketa
(Tukey's HSD, $\mathrm{p}=0.037$ ) with one house location different from the means of the other three. Low sample numbers and variation between sites could be due to the shorter sampling period than at other sampling locations. No samples from Saketa were found to be Plasmodium positive.

The biting profiles of mosquitoes by hour varied by species and by site (Fig. 3), with apparent distinct outdoor/ indoor preference by site. In Canti, hourly counts of HLC showed mosquitoes were active throughout the night, but were more prevalent after midnight both indoors and outdoors (Fig. 3a). In Kaliharjo, mosquitoes were trapped relatively consistently throughout the sampling period outdoors, but were rarely collected indoors (Fig. 3b). In Saketa, low catch numbers prevent statistical interpretations. However, there is an apparent peak of anophelines early in the evening using goat-baited tent traps (Fig. 3c).

\section{Discussion}

To evaluate trap efficacy at three sites in Indonesia representing different transmission environments, A Latin square design was used to compare seven collection techniques. This study suggests potential differences in mosquito behaviour in the three sites with respect to late night/early morning and indoor/outdoor biting behaviour. Trap efficacy likewise differs by site, and could be partly determined by species composition and location specific behavioural patterns (Table 4). In Canti, South Sumatra, indoor and outdoor HLCs were extremely effective for catching the anthropophilic primary vector of the area, An. sundaicus, including P. falciparum- and P. vivax-positive mosquitoes (Tables 2, 5, 6). In Kaliharjo, central Java, significantly more anophelines were collected in outdoor HLCs than any other trap tested, indicating that the local vector populations are exophagic but still anthropophilic. In Saketa, only a goat-baited tent collected meaningful numbers of anophelines, which may be highly zoophilic in this area, though this trap was not evaluated at the other two sites.

The comparative trap evaluation in Canti indicates that An. sundaicus are highly attracted to humans, both indoors and outdoors. While the host preference of these mosquitoes was not evaluated, they seek humans readily and are found infected with both $P$. vivax and $P$. falciparum. The elevated rate of $P$. vivax infection compared to $P$. falciparum is consistent with the risk estimates of malaria endemicity in Indonesia [33, 34]. While a number of mosquitoes were captured in three variations of tent traps in which humans are protected, the proportions of mosquitoes caught in these exposure-free tents were small compared to HLCs. Despite lower trap efficiency, the large and small human-occupied tents captured sporozoite positive mosquitoes, suggesting some 
Table 4 Total anophelines captured and mean catch with each collection method at three sites

\begin{tabular}{|c|c|c|c|c|c|c|}
\hline & \multicolumn{2}{|c|}{ Canti, Lampung } & \multicolumn{2}{|c|}{ Kaliharjo, Purworejo } & \multicolumn{2}{|c|}{ Saketa, Halmahera } \\
\hline & Total & Mean per night & Total & Mean per night & Total & Mean per night \\
\hline \multicolumn{7}{|c|}{ Mean anopheline catch per trap by site } \\
\hline $\mathrm{HLC}$ in & 827 & 51.7 & 14 & 0.9 & 3 & 0.4 \\
\hline HLC out & 1277 & 79.8 & 243 & 15.2 & 2 & 0.3 \\
\hline Large tent & 104 & 0.2 & 11 & 0.0 & 3 & 0.4 \\
\hline Small tent & 82 & 6.5 & 3 & 0.7 & 0 & 0.0 \\
\hline $\mathrm{ITT}$ & 13 & 5.1 & 1 & 0.2 & 0 & 0.0 \\
\hline CDC-LT & 41 & 0.8 & 0 & 0.1 & 1 & 0.0 \\
\hline Resting box in & 2 & 2.6 & 1 & 0.0 & 0 & 0.1 \\
\hline Resting box out & 2 & 0.1 & 0 & 0.1 & 0 & 0.0 \\
\hline Resting jar in & 3 & 0.1 & 0 & 0.0 & 0 & 0.0 \\
\hline Resting jar out & 2 & 0.1 & 0 & 0.0 & 0 & 0.0 \\
\hline Goat & - & - & - & - & 54 & 6.8 \\
\hline Total & 2353 & 147.1 & 273 & 17.1 & 63 & 7.9 \\
\hline
\end{tabular}

Total catch was divided by the number of catch nights for each trap. There were 16 catch nights for Canti and Kaliharjo, and 8 for Saketa. Traps vary in efficacy by site, reflecting site-by-site variation in anopheline behaviour and densities

Table 5 Trap efficacy for Anopheles sundaicus in Canti village, Lampung

\begin{tabular}{lccl}
\hline & $\begin{array}{l}\text { Total An. sundaicus } \\
\text { captured }\end{array}$ & $\begin{array}{l}\text { Mean catch } \\
\text { per night }\end{array}$ & $\begin{array}{l}\text { Trap efficacy } \\
\text { (compared } \\
\text { to HLC) }\end{array}$ \\
\hline $\begin{array}{l}\text { Indoor traps } \\
\text { HLC in }\end{array}$ & 827 & 51.7 & - \\
CDC-LT & 41 & 2.6 & 0.05 \\
Resting box in & 2 & 0.1 & 0.00 \\
Resting jar in & 3 & 0.2 & 0.00 \\
Outdoor traps & & & \\
HLC out & 1277 & 79.8 & - \\
Large tent & 104 & 6.5 & 0.08 \\
Small tent & 82 & 5.1 & 0.06 \\
ITT & 13 & 0.8 & 0.01 \\
Resting box out & 2 & 0.1 & 0.00 \\
Resting jar out & 2 & 0.1 & 0.00 \\
\hline
\end{tabular}

Trap efficacy was calculated by dividing the nightly mean of anophelines captured by each trap by the mean catch for human landing collection. CDC light trap, resting pot indoor, and resting box indoor collections were compared to HLC indoor catches. All other traps were compared to HLC outdoor catches. These collections occurred over 16 trap nights

possibility of their use as a monitoring tool in this area, though this may require using more traps to duplicate the capture rate of a single collector performing HLCs. However, the majority of Plasmodium-positive specimens were captured in HLCs, indicating that this remains a
Table 6 Sporozoite-positive mosquitoes by collection method

\begin{tabular}{|c|c|c|}
\hline & An. sundaicus & An. aconitus \\
\hline $\mathrm{HLC}$ in & $\begin{array}{l}16 P . V \\
3 P . f\end{array}$ & \\
\hline HLC out & $\begin{array}{l}31 P . V \\
6 P . f\end{array}$ & $2 P . V$ \\
\hline Large tent & 3P.V & \\
\hline Small tent & $3 P . V$ & \\
\hline CDC-LT & 5P.V & \\
\hline Total & $\begin{array}{l}62 P . V \\
9 P . f\end{array}$ & $2 P . V$ \\
\hline Sporozoite rate (\%) & $\begin{array}{l}2.6 \% \text { P.V } \\
0.4 \% \text { P.f }\end{array}$ & $0.7 \%$ P.V \\
\hline
\end{tabular}

P. $v$ denotes Plasmodium vivax positives. P. $f$ denotes Plasmodium falciparum positives. Sporozoite rates are calculated by dividing the number of positives by the total tested

An. sundaicus were collected in Canti, Lampung, An. aconitus were collected in Kaliharjo, Purworejo

valid and useful primary method for vector monitoring here.

Anopheline collections in Canti consisted entirely of An. sundaicus, indicating that this species was the primary malaria vector in this village during the collection period, and also active both indoors and outdoors throughout the night with slightly elevated activity after midnight. Anopheles sundaicus is a saline-tolerant mosquito and the larvae may thrive in small fish and shrimp 

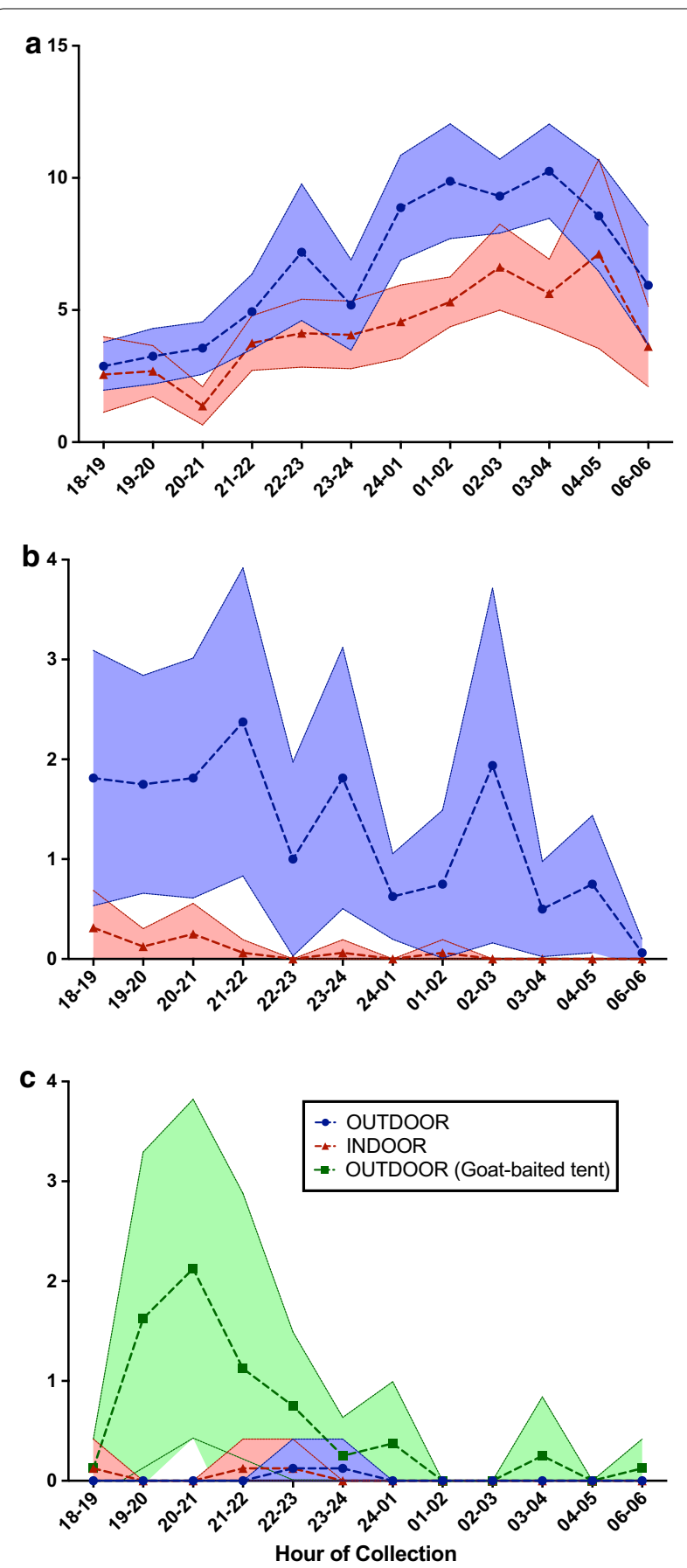

Fig. 3 Comparisons of mean hourly anopheline catch rates by indoor and outdoor human landing collection over 16 nights. In a Canti village, Lampung: indicates biting is present throughout the night, but peaks in the pre-dawn early morning. b Kaliharjo village, Purworejo: indicates biting is present mostly outdoors and appears to decline by early morning. c Saketa village, Halmahera (8 nights of collection): indicates biting of humans is mostly absent throughout the night, but zoophilic behaviour is present in the early evening. A goat-baited tent was only evaluated in Saketa. Mean number of mosquitoes caught are plotted as points on an hourly basis, with 95\% confidence interval bands farming facilities, which are common in the area along the coast [25]. Management of these breeding sites may help to control populations of An. sundaicus and to reduce malaria transmission. Other work in the area has shown that there is a greater diversity of Anopheles species inland, but large populations of An. sundaicus may serve to sustain malaria transmission foci along the coast. The parasites circulating in these foci could influence transmission in nearby inland areas or wider ranges through human movement and travel. The indoor and outdoor HLCs of An. sundaicus in this study were comparable, indicating that this species is more willing to enter houses than vectors in other parts of Indonesia. This may make $A n$. sundaicus more amenable to indoor control measures, such as ITNs or IRS.

In Kaliharjo, outdoor HLC was more effective than any other collection method, suggesting that anophelines in this area are attracted to humans, but are exophagic. If human-occupied tent traps are to be further evaluated in this area, they would likely need to be designed to have relatively unrestricted openings to encourage the local species to enter. Kaliharjo has a more diverse set of known vectors than Canti, and it is possible that this study missed some of the local anopheline species. Anopheles aconitus, An. barbirostris and An. Balabacensis, all captured in the area, are known secondary vectors. Further trap evaluations are necessary to fully explore the Anopheles species composition, and to make fully informed decisions on vector control monitoring strategies. Traps utilizing animal baits were not evaluated at all of the sites in this study, but have proven to be extremely successful in other areas of Indonesia and Southeast Asia and could help answer the question of local mosquito host preference [35].

Trapping in Saketa revealed that other trapping methods may be necessary for monitoring the diverse set of resident outdoor-biting and potentially zoophilic vectors. The goat-baited tent trap and other animal-baited traps should be further explored and expanded to other sampling locations in Indonesia. The malaria endemicity in this area is the highest of the three sampling locations in this study, yet the anopheline population was least attracted to humans in HLCs and in any type of humanoccupied tent trap, yielding much lower mean nightly catches compared to the other two sites. A comparison of light traps and landing catches in Papua New Guinea (PNG) revealed that light traps are more effective than indoor or outdoor HLCs in catching two members of the Anopheles punctulatus complex [36]. Other studies have shown that this area contains a different set of vectors than PNG, with very few mosquitoes from the An. punctulatus complex present [37]. Extremely high catch rates have been shown using cow baits compared to humans 
in tents at this same collection site [38]. Due to low HLC catches in this and some other areas, meaningful biting rates are difficult to calculate and various epidemiological measures, such as entomological inoculation rate (EIR), may need to be calculated from non-entomological measures such as serological infection rates [39]. Further sampling would be required to accurately determine trap efficacy in this site.

\section{Conclusions}

Human landing collection remains a valuable tool for estimating exposure of humans to potentially infectious bites from Anopheles mosquitoes, but may not be applicable in all transmission environments depending on resident Anopheles species behaviour. Indoor HLC failed to capture mosquitoes in two Indonesian sites, and HLCs were entirely ineffective in Saketa, a place with relatively higher malaria transmission than the other two study sites. In those areas where HLC is ineffective and malaria may be propagated by zoophilic or opportunistic mosquitoes, animal-baited trapping methods may be useful. Limitations of this study include small numbers of sampling nights, especially in Saketa, and the more cross-sectional nature of the study design. Longitudinal sampling efforts combined with monitoring malaria prevalence is necessary to better describe vector behaviour and species distributions during times of heightened or depressed transmission.

\section{Additional file}

Additional file 1: Table S1. Tukey's multiple comparisons tests for traps within each village.

\section{Authors' contributions}

BSTL, NFL, SS, TRB, FHC, DS, and WAH contributed to the conception and design of the study. SS, BSTL, Su, SF, AS, HS, Sh, MZ, SSu, and AB participated in the implementation of the study and entomological collections. DS, PBSA BSTL, DB, and SK participated in the molecular analysis, sequencing, and Plasmodium screening of field-collected specimens. BSTL and NFL carried out the sequence analysis and interpretation of the data. BSTL, NFL and TAB did the statistical analysis, generated the Figures, and drafted the manuscript. All authors contributed to the critical revision of the manuscript for intellectual content. All authors read and approved the final manuscript.

\section{Author details}

${ }^{1}$ Eck Institute for Global Health, University of Notre Dame, Notre Dame, IN, USA. ${ }^{2}$ National Institute of Health Research and Development, Jakarta, Indonesia. ${ }^{3}$ Eijkman Institute for Molecular Biology, Jakarta, Indonesia. ${ }^{4}$ Centers for Disease Control and Prevention, Atlanta, GA, USA. ${ }^{5}$ Unicef, Jakarta, Indonesia. ${ }^{6}$ National Institutes of Health, Bethesda, MD, USA. ${ }^{7}$ Queensland Tropical Health Alliance, James Cook University, Australian Institute of Tropical Health and Medicine, Cairns, Australia.

\section{Acknowledgements}

Special thanks to field assistants, collectors and laboratory assistants for specimen processing at the Eijkman Institute of Molecular Biology, Jakarta, Indonesia and the University of Notre Dame. Thanks to Julie Niedbalski and
Katie Cybulski for help and support at the University of Notre Dame, and to Endang Simiwi, Rita Kusriastuti, and P.R. Arbani for their support.

\section{Competing interests}

The authors declare that they have no competing interests.

\section{Availability of data and materials}

This article is published open access. The datasets generated and analysed during the current study are available from the corresponding author upon reasonable request.

\section{Consent for publication}

Not applicable.

\section{Ethics approval and consent to participate}

The need for ethics approval for non-human subjects (which was determined to include performing HLCs and using animal-baited tents) was waived by the University of Notre Dame. The State Minister for Research and Technology of The Republic of Indonesia approved the study in 2009 and also waived the need for a formal ethics approval. HLCs and animal-baited trapping were performed under the supervision of Dr. Sukowati Supratman of the Indonesian National Institute of Health Research and Development.

\section{Funding}

This project has been funded in whole or in part by the Bill and Melinda Gates Foundation under Grant No. 45114.

\section{Publisher's Note}

Springer Nature remains neutral with regard to jurisdictional claims in published maps and institutional affiliations.

Received: 23 May 2017 Accepted: 23 December 2017

Published online: 08 January 2018

\section{References}

1. Bhatt S, Weiss DJ, Cameron E, Bisanzio D, Mappin B, Dalrymple U, et al. The effect of malaria control on Plasmodium falciparum in Africa between 2000 and 2015. Nature. 2015:526:207-11.

2. WHO. World malaria report 2016. Geneva: World Health Organization; 2016.

3. Lobo NF, St. Laurent B, Sikaala CH, Hamainza B, Chanda J, Chinula D, et al. Unexpected diversity of Anopheles species in Eastern Zambia: implications for evaluating vector behavior and interventions using molecular tools. Sci Rep. 2015:5:17952

4. St. Laurent B, Cooke M, Krishnankutty SM, Asih P, Mueller JD, Kahindi S, et al. Molecular characterization reveals diverse and unknown malaria vectors in the western Kenyan highlands. Am J Trop Med Hyg 2016:94:327-35.

5. Parker DM, Carrara VI, Pukrittayakamee S, McGready R, Nosten FH. Malaria ecology along the Thailand-Myanmar border. Malar J. 2015;14:388.

6. Takken W. Do insecticide treated bednets have an effect on malaria vectors? Trop Med Int Health. 2002;7:1022-30.

7. Killeen GF, Govella NJ, Lwetoijera DW, Okumu FO. Most outdoor malaria transmission by behaviourally resistant Anopheles arabiensis is mediated by mosquitoes that have previously been inside houses. Malar J. 2016;15:225.

8. Russell TL, Govella NJ, Azizi S, Drakeley CJ, Kachur SP, Killeen GF. Increased proportions of outdoor feeding among residual malaria vector populations following increased use of insecticide-treated nets in rural Tanzania. Malar J. 2011;10:80

9. Ranson H, Guessan RN, Lines J, Moiroux N, Nkuni Z, Corbel V. Pyrethroid resistance in African anopheline mosquitoes: what are the implications for malaria control? Trends Parasitol. 2011;27:91-8.

10. Meyers Jl, Pathikonda S, Hall ZRP, Medeiros MC, Fuseini G, Matias A, et al. Increasing outdoor host seeking in Anopheles gambiae over 6 years of vector control on Bioko Island. Malar J. 2016;15:239. 
11. Reddy MR, Overgaard HJ, Abaga S, Reddy VP, Caccone A, Kiszewski AE, et al. Outdoor host seeking behaviour of Anopheles gambiae mosquitoes following initiation of malaria vector control on Bioko Island, Equatorial Guinea. Malar J. 2011;10:184.

12. Mwangangi JM, Mbogo CM, Orindi BO, Muturi EJ, Midega JT, Nzovu $J$, et al. Shifts in malaria vector species composition and transmission dynamics along the Kenyan coast over the past 20 years. Malar J. 2013;12:13.

13. Gatton ML, Chitnis N, Churcher T, Donnelly MJ, Ghani AC, Godfray HCJ, et al. The importance of mosquito behavioral adaptations to malaria control in Africa. Evolution (NY). 2013;67:1218-30.

14. Bidlingmayer WL. A comparison of trapping methods for adult mosquitoes: species response and environmental influence. J Med Entomol. 1967:4:200-20.

15. Overgaard HJ, Sæbø S, Reddy MR, Reddy VP, Abaga S, Matias A, et al. Light traps fail to estimate reliable malaria mosquito biting rates on Bioko Island, Equatorial Guinea. Malar J. 2012;11:56.

16. Govella NJ, Chaki PP, Geissbuhler Y, Kannady K, Okumu F, Charlwood JD, et al. A new tent trap for sampling exophagic and endophagic members of the Anopheles gambiae complex. Malar J. 2009:8:157.

17. Gimnig JE, Walker ED, Otieno P, Kosgei J, Olang G, Ombok M, et al. Incidence of malaria among mosquito collectors conducting human landing catches in western Kenya. Am J Trop Med Hyg. 2013;88:301-8.

18. Mboera LEG. Sampling techniques for adult Afrotropical malaria vectors and their reliability in the estimation of entomological inoculation rate. Tanzan Health Res Bull. 2005;7:117-24.

19. Govella NJ, Moore JD, Killeen GF. An exposure-free tool for monitoring adult malaria mosquito populations. Am J Trop Med Hyg. 2010;83:596-600.

20. Sikulu M, Govella NJ, Ogoma SB, Mpangile J, Kambi SH, Kannady K, et al. Comparative evaluation of the Ifakara tent trap- $\mathrm{B}$, the standardized resting boxes and the human landing catch for sampling malaria vectors and other mosquitoes in urban Dar es Salaam, Tanzania. Malar J. 2009:8:197.

21. Sikaala CH, Killeen GF, Chanda J, Chinula D, Miller JM, Russell TL, et al. Evaluation of alternative mosquito sampling methods for malaria vectors in Lowland South-East Zambia. Parasites Vectors. 2013;6:91.

22. Wong J, Bayoh N, Olang G, Killeen GF, Hamel MJ, Vulule JM, et al. Standardizing operational vector sampling techniques for measuring malaria transmission intensity: evaluation of six mosquito collection methods in western Kenya. Malar J. 2013;12:143.

23. WHO/SEARO. Anopheline species complexes in South and South-East Asia. New Delhi: Worth Health Organization, SEARO; 2007

24. Stoops CA, Gionar YR, Shinta, Sismadi P, Elyazar IRF, Bangs MJ, et al. Environmental factors associated with spatial and temporal distribution of Anopheles (Diptera: Culicidae) larvae in Sukabumi, West Java, Indonesia. J Med Entomol. 2007;44:543-53.

25. Dusfour I, Harbach RE, Manguin S. Bionomics and systematics of the oriental Anopheles sundaicus complex in relation to malaria transmission and vector control. Am J Trop Med Hyg. 2004;71:518-24.
26. Stoops CA, Rusmiarto S, Susapto D, Munif A, Andris H, Barbara KA, et al. Bionomics of Anopheles spp. (Diptera: Culicidae) in a malaria endemic region of Sukabumi, West Java, Indonesia. J Vector Ecol. 2009;34:200-7.

27. Barcus MJ, Laihad F, Sururi M, Sismadi P, Marwoto H, Bangs MJ, et al. Epidemic malaria in the Menoreh Hills of central java. Am J Trop Med Hyg. 2002;66:287-92.

28. Govella NJ, Chaki PP, Mpangile JM, Killeen GF. Monitoring mosquitoes in urban Dar es Salaam: evaluation of resting boxes, window exit traps, CDC light traps, Ifakara tent traps and human landing catches. Parasites Vectors. 2011;4:40.

29. O'Connor C, Soepanto A. Illustrated key to female anophelines of Indonesia. Jakarta: Directorate of Communicable Disease, Ministry of Health; 1989.

30. Beebe NW, Saul A. Discrimination of all members of the Anopheles punctulatus complex by polymerase chain reaction-restriction fragment length polymorphism analysis. Am J Trop Med Hyg. 1995;53:478-81.

31. Burkot TR, Zavala F, Gwadz RW, Collins FH, Nussenzweig RS, Roberts DR. Identification of malaria-infected mosquitoes by a two-site enzymelinked immunosorbent assay. Am J Trop Med Hyg. 1984;33:227-31.

32. Singh B, Bobogare A, Cox-Singh J, Snounou G, Abdullah MS, Rahman HA. A genus-and species-specific nested polymerase chain reaction malaria detection assay for epidemiologic studies. Am J Trop Med Hyg. 1999;60:687-92.

33. Elyazar IRF, Gething PW, Patil AP, Rogayah H, Kusriastuti R, Desak M, et al. Plasmodium falciparum malaria endemicity in Indonesia in 2010. PLoS ONE. 2011;6:e21315.

34. Elyazar IRF, Gething PW, Patil AP, Rogayah H, Sariwati E, Palupi NW, et al. Plasmodium vivax malaria endemicity in Indonesia in 2010. PLoS ONE. 2012; 7:e37325

35. St. Laurent B, Oy K, Miller B, Gasteiger EB, Lee E, Sovannaroth S, et al. Cowbaited tents are highly effective in sampling diverse Anopheles malaria vectors in Cambodia. Malar J. 2016;15:440.

36. Hii JLK, Smith T, Mai A, Ibam E, Alpers MP. Comparison between anopheline mosquitoes (Diptera: Culicidae) caught using different methods in a malaria endemic area of Papua New Guinea. Bull Entomol Res. 2000;90:211-9.

37. Elyazar IRF, Sinka ME, Gething PW, Tarmidzi SN, Surya A, Kusriastuti R, et al. The distribution and bionomics of Anopheles malaria vector mosquitoes in Indonesia. Adv Parasitol. 2013;83:173-266.

38. St. Laurent B, Burton TA, Zubaidah S, Miller HC, Asih PB, Baharuddin A, et al. Host attraction and biting behaviour of Anopheles mosquitoes in South Halmahera, Indonesia. Malar J. 2017;16:310.

39. Olotu A, Fegan G, Wambua J, Nyangweso G, Ogada E, Drakeley C, et al. Estimating individual exposure to malaria using local prevalence of malaria infection in the field. PLoS ONE. 2012;7:e32929.

\section{Submit your next manuscript to BioMed Central and we will help you at every step:}

- We accept pre-submission inquiries

- Our selector tool helps you to find the most relevant journal

- We provide round the clock customer support

- Convenient online submission

- Thorough peer review

- Inclusion in PubMed and all major indexing services

- Maximum visibility for your research

Submit your manuscript at www.biomedcentral.com/submit 